\title{
Application of QSAR models in analysis of antibacterial activity of some benzimidazole derivatives against Sarcina lutea
}

\author{
Sanja O. Podunavac-Kuzmanović, Dragoljub D. Cvetković, Lidija R. Jevrić, Nataša U. Uzelac \\ University of Novi Sad, Faculty of Technology, Novi Sad, Serbia
}

\begin{abstract}
In the present study, a quantitative structure activity relationship (QSAR) has been carried out on a series of 2-methyl and 2-aminobenzimidazole derivatives to identify the lipophilicity requirements for their inhibitory activity against bacteria Sarcina lutea. The tested compounds displayed in vitro antibacterial activity and minimum inhibitory concentration (MIC) was determined for all compounds. The partition coefficients of the studied compounds were measured by the shake flask method $(\log P)$ and by theoretical calculation $(C \log P)$. The relationships between lipophilicity descriptors and antibacterial activities were investigated and the mathematical models have been developed as a calibration models for predicting the inhibitory activity of this class of compounds. The models were validated by the leave-one-out (LOO) technique as well as by the calculation of statistical parameters for the established models. Therefore, QSAR analysis reveals that the lipophilicity descriptor governs the inhibitory activity of benzimidazoles studied against Sarcina lutea.
\end{abstract}

Keywords: benzimidazole, QSAR, lipophilicity, antibacterial activity, Sarcina lutea.

\section{SCIENTIFIC PAPER}

UDC 615.281:547.78:66

Hem. Ind. 67 (1) 27-33 (2013)

doi: 10.2298/HEMIND120313054P

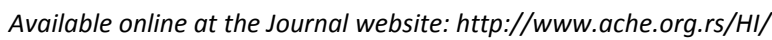

Benzimidazole derivatives continue to attract great interest due to the wide variety of interesting antimicrobial activities observed for this class of molecules. Several thousands of benzimidazole analogs have been synthesized and screened for pharmacological activity. They are of wide interest because of their diverse biological activity and clinical applications. These heterocyclic systems have different activities as they can act as bacteriostats or bactericides, as well as fungicides [1-5] and they are present in numerous antiparasitic, antitumoral and antiviral drugs [6-7]. Also, some of them exhibit appreciable antiprotozoal activity [8]. They were confirmed to have a moderate in vitro anti-HIV activity [9]. The success with this group of molecules stimulated the search for new biologically active derivatives. Understanding the role of chemical structure on biological activity is very important. Predictions of biological and physicochemical properties of molecules based on their structures are the fundamental and most interesting objectives of chemistry.

A large number of research studies are needed to analyze the pharmacophore present in these compounds using the three-dimensional QSAR methods. The physicochemical properties predicted from structure are helpful in the search for new molecules of similar or increased biological activity. The QSAR studies enable the scientists to establish reliable quanti-

Correspondence: S.O. Podunavac-Kuzmanović, Department of Applied and Engineering Chemistry, Faculty of Technology, University of Novi Sad, Bulevar cara Lazara 1, 21000 Novi Sad, Serbia.

E-mail: sanya@uns.ac.rs

Paper received: 13 March, 2012

Paper accepted: 15 May, 2012 tative relationships, to derive a QSAR model and predict the activity of novel molecules prior to their synthesis [10-13]. These studies reduce the trial and error element in the design of compounds by establishing mathematical relationships between physical, chemical, biological, or environmental activities of interest and measurable or computable parameters such as physicochemical, electronic, topological, or stereochemistry. The 3D-QSAR methodology has been successfully used to generate models for various chemotherapeutic agents.

Progress in the use of QSAR methods has shown the importance of the hydrophobic or lipophilic nature of drug molecules. The lipophilicity modifies the penetration of bioactive molecules through the apolar cell membranes. This property is usually characterized by partition coefficient $(\log P)$, which is essentially determined from distribution studies of the drug between an immiscible polar and non-polar solvent pair. This quantitative descriptor of lipophilicity is one of the key determinants of pharmacokinetic properties. By knowing exact values of this parameter, it is possible to predict the inhibitory activity of the drugs.

In view of the above and in continuation of our studies on inhibitory activities of benzimidazole derivatives [14-21], as well as on the correlation of molecular properties with inhibitory activity, the aim of this investigation was to study the usefulness of QSAR in the prediction of the antibacterial activity of benzimidazole derivatives against Sarcina lutea. The main objective of this study was to derive high-quality models which would link the lipophilicity of these compounds with their antibacterial activity. 


\section{EXPERIMENTAL}

Chemical structures of the benzimidazoles tested in this study are presented in Table 1.

Table 1. Chemical structures of benzimidazoles examined

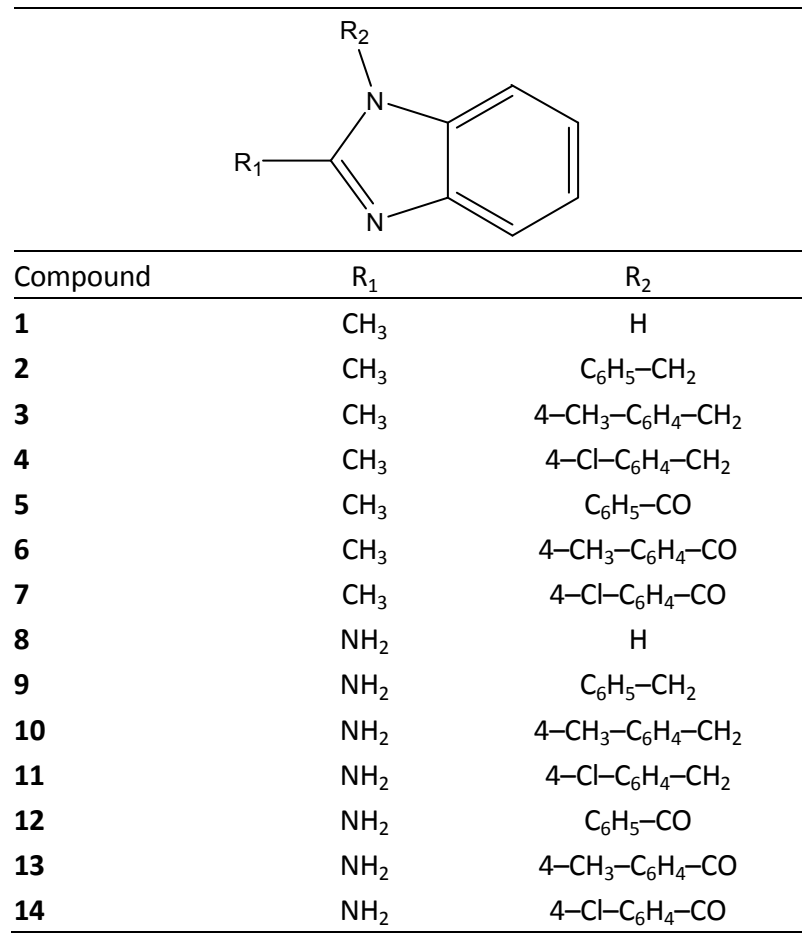

All the compounds except 1 and $\mathbf{8}$ were synthesized by a general procedure described by Vlaović [22]. 2-methylbenzimidazole (1) and 2-aminobenzimidazole (8) were of analytical reagent grade, commercially available.

\section{Procedure for experimental determination of antibacterial activity}

All the benzimidazole derivatives were evaluated for their in vitro growth inhibitory activity against Gram-positive bacteria Sarcina lutea. Antibacterial activities of the compounds were tested by the discdiffusion method under standard conditions using Mueller-Hinton agar medium as described by NCCLS [23]. The investigated isolate of bacteria was seeded in the tubes with nutrient broth (NB). A volume of $1 \mathrm{~cm}^{3}$ of seeded NB was taken and homogenized in tubes with $9 \mathrm{~cm}^{3}$ of melted $\left(45^{\circ} \mathrm{C}\right)$ nutrient agar (NA). The homogenous suspension was poured out in Petri dishes. The discs of filter paper (diameter $6 \mathrm{~mm}$ ) were ranged on cool medium. After cooling on formed solid medium, $1 \times 10^{-5} \mathrm{dm}^{3}$ of the investigated compounds ( $\gamma=$ $=1000 \mu \mathrm{g} / \mathrm{ml}$ ) were placed with a micropipette. After incubation for $24 \mathrm{~h}$ in a thermostat at $37^{\circ} \mathrm{C}$, inhibition (sterile) zone diameters (including disc) were measured (in $\mathrm{mm}$ ). Each test was performed in triplicate.
Minimum inhibitory concentration (MIC) was obtained by the broth dilution method according to the guidelines established by the NCCLS standard M7-A5 [24]. The MIC of tested benzimidazoles is defined as the lowest concentration of the compound at which no growth of the strain was observed in a specified period of time and under specified experimental conditions. Stock solutions of the compounds were prepared in dimethylformamide (DMF), and dilutions were performed with distilled water. The inoculated plates were than incubated at $37{ }^{\circ} \mathrm{C}$ for 20-24 h. A control (DMF without test compound) was included for each of the organisms. There was no inhibitory activity in the wells containing only DMF. The MIC values of the benzimidazoles tested were obtained as $\mu \mathrm{g} / \mathrm{ml}$. For further QSAR analyses, the negative logarithms of molar MICs (pMIC) were used.

\section{Molecular modeling and calculations of lipophilicity parameters}

Molecular modeling studies were performed using CS Chem-Office Software version 7.0 (Cambridge software) running on a P-III processor [25]. All molecules were constructed by using Chem Draw Ultra 7.0 and saved as the template structures. For every compound, the template structure was suitably changed considering its structural features, copied to Chem 3D 7.0 to create a $3 D$ model and, finally, the model was cleaned up and subjected to energy minimization using molecular mechanics $\left(\mathrm{MM}_{2}\right)$. The minimization was executed until the root mean square (RMS) gradient value reached a value smaller than $0.1 \mathrm{kcal} / \mathrm{mol} \cdot \mathrm{A}$. The Austin Model-1 (AM-1) method was used for re-optimization until the RMS gradient attained a value smaller than $0.0001 \mathrm{kcal} / \mathrm{mol} \cdot \mathrm{A}$ using MOPAC. The lowest energy structure was used for each molecule to calculate lipophilicity descriptors by using ChemDraw Ultra 7.0 (Table 2).

\section{Procedure for experimental determination of $\log P$}

For all the compounds the lipophilicity parameters, $\log P$ values, were experimentally determined by the shake flask method. Partition coefficients, $P$, for benzimidazoles investigated between n-octanol and phosphate buffer were determined at $25{ }^{\circ} \mathrm{C}$. Before the partitioning of benzimidazoles, the buffer $(0.15 \mathrm{~mol}$ $\mathrm{dm}^{-3}, \mathrm{pH}$ 7.4) and n-octanol (99\%, Sigma, USA) were saturated with each other. Benzimidazoles were dissolved in ethanol (96\%, Zorka, Serbia) at a concentration of $2 \mathrm{mg} \mathrm{cm}^{-3}$ to give the stock solution. Calibration was done in exactly the same manner as the partitioning, except that $n$-octanol was not used. The amounts of the sample were chosen so that absorbance $(\lambda=252 \mathrm{~nm})$ of 0.1 to 0.8 was measured. Partitioning experiments were performed in the systems $n$-octanol/phosphate buffer 1:20, 1:30, 1:70 and 
1:80 (V/V). All solutions were pipetted into glass vials; the $n$-octanol and stock solution were added with a microliter sxringe. The phases were shaken together on a mechanical shaker (Viggo, Sweden) for $30 \mathrm{~min}$, centrifuged (Rotofix, Switzerland) at $2500 \mathrm{rpm}$ for $20 \mathrm{~min}$ to afford complete phase separation, and n-octanol phase was removed. Absorbance of the buffer phase was measured using Shimadzu UV/VIS spectrophotometer (Japan) at $\lambda=252 \mathrm{~nm}$. Values of log $P$ were calculated as:

Table 2. Lipophilicity descriptors obtained experimentally (log P) and by theoretical calculation (Clog P)

\begin{tabular}{lcc}
\hline Compound & $\log P$ & $C \log P$ \\
\hline $\mathbf{1}$ & 1.53 & 1.48 \\
$\mathbf{2}$ & 3.51 & 3.45 \\
$\mathbf{3}$ & 4.01 & 3.94 \\
$\mathbf{4}$ & 4.07 & 4.01 \\
$\mathbf{5}$ & 3.38 & 3.33 \\
$\mathbf{6}$ & 3.87 & 3.81 \\
$\mathbf{7}$ & 3.95 & 3.89 \\
$\mathbf{8}$ & 1.05 & 0.99 \\
$\mathbf{9}$ & 3.02 & 2.96 \\
$\mathbf{1 0}$ & 3.50 & 3.44 \\
$\mathbf{1 1}$ & 3.59 & 3.52 \\
$\mathbf{1 2}$ & 2.90 & 2.84 \\
$\mathbf{1 3}$ & 3.35 & 3.32 \\
\hline
\end{tabular}

$$
\log P=\left(\frac{y-x}{x} \frac{V_{\text {buffer }}}{V_{n \text {-octanol }}}\right)
$$

where: $P$ - partition coefficient; $y$ - total mass of benz- imidazole derivative $(\mathrm{mg}) ; X$ - mass of benzimidazole derivative in the buffer phase after partitioning (mg); $V_{\text {buffer }}-$ volume of phosphate buffer $\left(\mathrm{cm}^{3}\right) ; V_{n \text {-octanol }}-$ volume of $n$-octanol $\left(\mathrm{cm}^{3}\right)$. Each experimental log $P$ value is the average of five determinations (Table 2 ).

\section{Statistical methods}

The complete regression analysis was carried out by PASS 2005, GESS 2006, NCSS Statistical Software [26].

\section{RESULTS AND DISCUSSION}

The results of antibacterial studies of 14 benzimidazole derivatives against Gram-positive bacteria Sarcina lutea are summarized in Table 3. As evident, all the compounds show noteworthy antibacterial activities against the tested bacteria. Consequently, the compounds with high value of pMIC (or low MIC) are the best antibacterial agents.

The antibacterial activity of the investigated benzimidazoles was compared with the activity of well known commercial antibacterial agents (Ampicillin and Gentamicin) which were screened under similar conditions as reference drugs.

In an effort to determine the role of structural features, QSAR study was undertaken. A set of benzimidazoles consisting of fourteen molecules was used for model generation. The reference drugs were not included in model generation as they belong to a different structural series. Inhibitory activity data (pMIC) were used as a dependent variable in the QSAR study.

The lipophilicity descriptors were used as independent variables and were correlated with inhibitory acti-

Table 3. Data of antibacterial activity obtained experimentally (pMICexp.) and by calculation (pMICpredict.)

\begin{tabular}{lccccc}
\hline \multirow{2}{*}{ Compound } & pMICexp. & \multicolumn{2}{c}{ pMICpred. } & \multicolumn{2}{c}{ Residuals } \\
\cline { 3 - 6 } & & Model 1 & Model 2 & Model 1 & Model 2 \\
\hline $\mathbf{1}$ & 4.635 & 4.510 & 4.525 & 0.125 & 0.110 \\
$\mathbf{2}$ & 4.435 & 4.527 & 4.529 & -0.092 & -0.094 \\
$\mathbf{3}$ & 3.488 & 3.439 & 3.590 & 0.049 & -0.102 \\
$\mathbf{4}$ & 3.424 & 3.432 & 3.425 & -0.008 & -0.001 \\
$\mathbf{5}$ & 4.688 & 4.711 & 4.701 & -0.023 & -0.013 \\
$\mathbf{6}$ & 3.712 & 3.879 & 3.875 & -0.167 & -0.163 \\
$\mathbf{7}$ & 3.747 & 3.708 & 3.703 & 0.039 & 0.044 \\
$\mathbf{8}$ & 3.536 & 3.595 & 3.584 & -0.059 & -0.048 \\
$\mathbf{9}$ & 4.965 & 5.086 & 5.093 & -0.121 & -0.128 \\
$\mathbf{1 0}$ & 4.688 & 4.542 & 4.544 & 0.146 & 0.144 \\
$\mathbf{1 1}$ & 4.725 & 4.400 & 4.418 & 0.325 & 0.307 \\
$\mathbf{1 2}$ & 4.991 & 5.167 & 5.174 & -0.176 & -0.183 \\
$\mathbf{1 3}$ & 4.714 & 4.750 & 4.715 & -0.036 & -0.001 \\
$\mathbf{1 4}$ & 4.749 & 4.615 & 4.618 & 0.134 & 0.131 \\
Ampicillin & 4.446 & & & & - \\
Gentamicin & 5.787 & & & & - \\
\hline
\end{tabular}


vity. The lipophilicity parameters tend to correlate with inhibitory activity, but in a more general case this relationship is not linear. Therefore, a regression analysis was made resorting to both linear and quadratic. The statistical quality of the generated models is determined by statistical measures: correlation coefficient, $r$, the standard error of estimation, $s$, and F-test (Fisher's value) for statistical significance [27-29] (Table 4). The correlation coefficient is a relative measure of the fit by the regression equation. Correspondingly, it represents the part of variation in the observed data that is explained by the regression. The correlation coefficient values closer to 1.0 represent the better fit of the regression. Standard deviation is measured by the error mean square, which expresses the variation of the residuals or the variation about the regression line. Thus, standard deviation is an absolute measure of the quality of fit and should have a low value for the regression to be significant. The $F$-test reflects the ratio of the variance explained by the model and the variance due to the error in regression. High values of the $F$-test indicate that the model is statistically significant.

It is observed that fitting equations improve when resorting to second order polynomials. In this approach, two similar mathematical models were derived (Table 4). Both the models were derived using entire data set of compounds $(n=14)$ and no outliers were identified. It is noteworthy that the correlation between pMIC, and shake flask $\log P$, as well as correlation between PMIC, and Clog $P$ were equally significant. From the results, it can be concluded that theoretical calculated $C \log P$ values can be used instead of $\log P$ values measured by the conventional shake-flask technique. This is a rapid and reliable method to predict the antibacterial activity of this class of molecules.

However, there are three important components in any QSAR study: development of models, validation of models and utility of developed models. Validation is a crucial aspect of any QSAR analysis [30]. The statistical quality of the resulting models, as depicted in Table 4, is determined by $r$, $s$ and $F[31-33]$.

For the testing the validity of the predictive power of selected models the LOO technique was used. The developed models were validated by the calculation of the following statistical parameters: PRESS, SSY, $S_{\text {PRESS, }}$ $r_{\mathrm{cv}}^{2}$ and $r_{\text {adj }}^{2}$ (Table 5).

These parameters were calculated from the following equations.

$$
\begin{aligned}
& \text { PRESS }=\sum\left(Y_{\text {obs }}-Y_{\text {calc }}\right)^{2} \\
& S S Y=\sum\left(Y_{\text {obs }}-Y_{\text {mean }}\right)^{2} \\
& S_{\text {PRESS }}=\sqrt{\frac{P R E S S}{n}} \\
& r_{\mathrm{CV}}^{2}=1-\frac{P R E S S}{S S Y} \\
& r_{\text {adj }}^{2}=1-r^{2}\left(\frac{n-1}{n-p-1}\right)
\end{aligned}
$$

where $Y_{\text {obs, }} Y_{\text {calc }}$ and $Y_{\text {mean }}$ are observed, calculated and mean values; $n$ is the number of compounds; and $p$ is the number of independent parameters.

PRESS is an acronym for prediction sum of squares. It is used to validate a regression model with regards to predictability. To calculate PRESS, each observation is individually omitted. The remaining $n-1$ observations are used to calculate a regression and estimate the value of the omitted observation. This is done $n$ times, once for each observation. The difference between the actual $Y$ value, $Y_{\text {obs, }}$ and the predicted $Y, Y_{\text {calc }}$, is called the prediction error. The sum of the squared prediction errors is the PRESS value. The smaller PRESS is, the better the predictability of the model. Its value being less than SSY points out that the model predicts better than chance and can be considered statistically significant. SSY are the sums of squares associated with the corresponding sources of variation. These values are in

Table 4. Statistical parameters of the best mathematical models for the prediction of antibacterial activity

\begin{tabular}{lcccccc}
\hline Model & \multicolumn{1}{c}{ Coefficient } & & $n$ & $r$ & $s$ & $F$ \\
\hline 1 & Intercept & 0.3514 & 14 & 0.9715 & 0.0233 & 92.2480 \\
& $\log P$ & 3.8998 & & & \\
& $(\log P)^{2}$ & -0.7721 & & & & \\
2 & Intercept & 0.5416 & 14 & 0.9728 & 0.0222 & 96.8987 \\
& $C \log P$ & 3.8451 & & & \\
& $(\operatorname{Clog} P)^{2}$ & -0.7795 & & & & \\
& & & & & & \\
\end{tabular}

Table 5. Cross-validation parameters

\begin{tabular}{lcccccc}
\hline Model & PRESS & SSY & PRESS/SSY & $S_{\text {PRESS }}$ & $r_{\text {CV }}^{2}$ & $r_{\text {adj }}^{2}$ \\
\hline 1 & 0.4005 & 4.5605 & 0.0878 & 0.1691 & 0.9122 & 0.9335 \\
2 & 0.3738 & 4.5605 & 0.0820 & 0.1634 & 0.9180 & 0.9365 \\
\hline
\end{tabular}


terms of the dependent variable, $Y$.

The PRESS value above can be used to compute an $r^{2}$ cv statistic, called $r^{2}$ cross validated, which reflects the prediction ability of the model. This is a good way to validate the prediction of a regression model without selecting another sample or splitting data. It is very possible to have a high $r^{2}$ and a very low $r_{\mathrm{Cv}}^{2}$. When this occurs, it implies that the fitted model is data dependent. This $r_{c v}^{2}$ ranges from below zero to above one. When outside the range of zero to one, it is truncated to stay within this range. Adjusted $r$-squared $\left(r^{2}\right.$ adj $)$ is an adjusted version of $r^{2}$. The adjustment seeks to remove the distortion due to a small sample size.

In many cases $r_{\mathrm{CV}}^{2}$ and $r_{\text {adj }}^{2}$ is taken as a proof of the high predictive ability of QSAR models. A high value of these statistical characteristic $(>0.5)$ is considered as a proof of the high predictive ability of the model. But, recent reports have proved the opposite [31]. Although, the low value of $r^{2}$ cv for the training set can indeed serve as an indicator of a low predictive ability of a model, the opposite is not necessarily true. Indeed, the high $r_{\text {cv }}^{2}$ does not imply automatically a high predictive ability of the model. Thus, the high value of LOO $r_{\mathrm{cv}}^{2}$ is the necessary condition for a model to have a high predictive power, but it is not a sufficient condition.

The only way to estimate the true predictive power of a model is to test its ability to predict accurately the biological activities of compounds.

To confirm the predictive power of the models, the inhibitory activity of 14 molecules included in the study was calculated by the theoretical models (1) and (2). The data presented in Table 3 show that the observed and the estimated activities are very close to each other. It indicates the good predictability of the established models. Figure 1 shows the plots of linear regression predicted versus experimental values of the antibacterial activity of benzimidazoles investigated. To investigate the existence of a systemic error in developing the QSAR models, the residuals of predicted values of inhibitory activity were plotted against the experimental values in Figure 2. The propagation of the residuals on both sides of zero indicates that no systemic error exists in the development of regression models as suggested by Jalali-Heravi and Kyani [32]. It indicates that these models can be successfully applied to predict the antibacterial activity of this class of molecules.

Analysis of the results indicates that the antibacterial activity exhibited by tested compounds is governed by the lipophilicity parameter, that is $\log P$. It can be concluded that strong influence of the partition coefficient, $\log P$, is important for the antibacterial activity and this parameter is usually related to pharmacological activity. This evidence was clearly des- cribed in lipid theory advanced by Meyer and Overton $[33,34]$. According to this theory, $\log P$ is a measure of hydrophobicity which is important for the penetration and distribution of the drug, but also for the interaction of drug with receptors. The results of this study indicate that both shake flask $\log P$ and $C \log P$ are equaly suitable for prediction of partition coefficient.

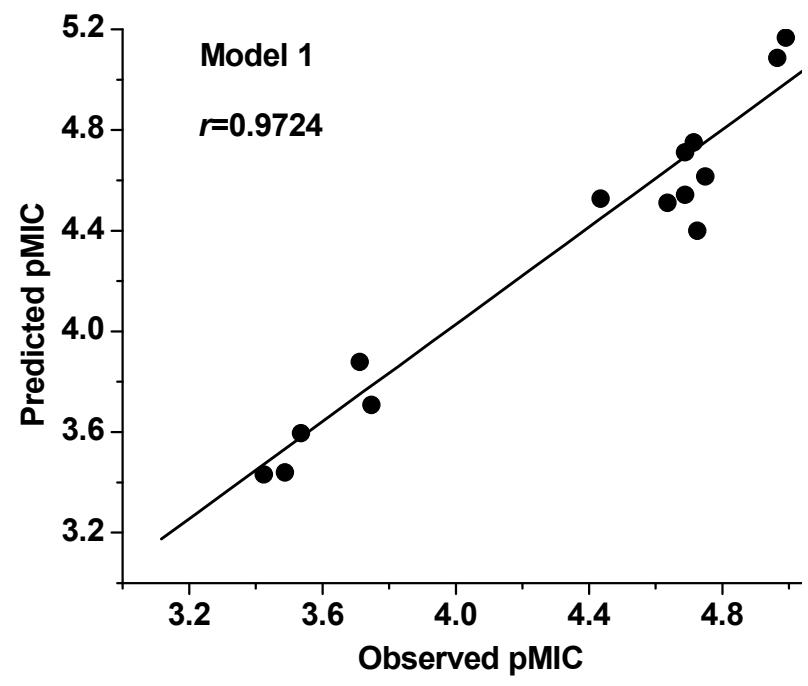

Figure 1. Relationship between pMIC values obtained experimentally and by calculation.

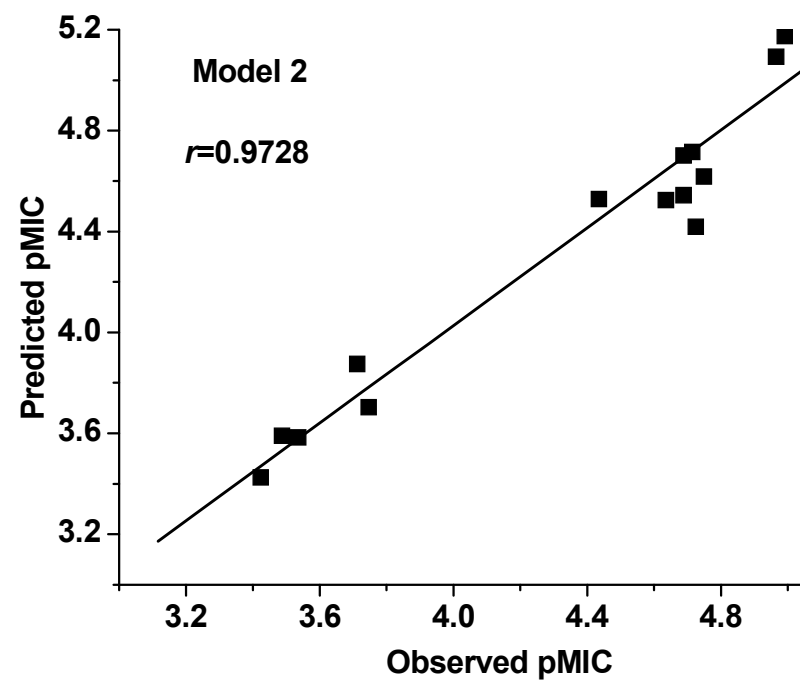

Figure 2. Relationship between the residual values and pMIC values obtained experimentally.

\section{CONCLUSION}

From the results and discussion above, we conclude that the 2-amino- and 2-methylbenzimidazole derivatives are effective in vitro against the Gram-positive bacteria Sarcina lutea. Molecular modeling and QSAR analysis were performed to find the quantitative effects of the lipophilicity of the compounds on their antibacterial activity. Accurate mathematical models 
were developed for predicting the inhibitory activity of some benzimidazole derivatives. The validity of the models has been established by the determination of suitable statistical parameters. The established models were used to predict inhibitory activity of the benzimidazoles investigated and close agreement between experimental and predicted values was obtained. The low residual activity and high cross-validated $r^{2}$ values $\left(r_{\mathrm{cv}}^{2}\right)$ observed indicated the predictive ability of the developed QSAR models. It indicates that the antibacterial activity of series of 2-amino- and 2-methylbenzimidazole derivatives can be successfully modeled using both shake flask $\log P$ and $C \log P$.

\section{Acknowledgment}

These results are part of the project No. 172012 and No. 172014 financially supported by the Ministry of Education, Science and Technological development of the Republic of Serbia, 2011-2014, and the project No. 114-451-2373/2011, financially supported by the Provincial Secretariat for Science and Technological Development of Vojvodina.

\section{REFERENCES}

[1] Z. Ates-Alagoz, S. Yildiz, E. Buyukbingol, Antimicrobial activities of some tetrahydronaphthalene-benzimidazole derivatives, Chemotherapy 53 (2007) 110-113.

[2] P.T.M. Nguyen, J.D. Baldeck, J. Olsson, R.E. Marquis, Antimicrobial actions of benzimidazoles against oral streptococci, Oral Microbiol. Immunol. 20 (2005) 93-99.

[3] G. Ayhan-Kilcigil, N. Altanlar, Synthesis and antifungal properties of novel benzimidazole derivatives, Turk. J. Chem. 30 (2006) 223-228.

[4] H. Goker, M. Alp, S. Yildiz, Synthesis and Potent Antimicrobial activity of some novel $\mathrm{N}$-(alkyl)-2-phenyl- $1 \mathrm{H}$ benzimidazole-5-carboxamidines, Molecules 10 (2000) 1377-1386

[5] S.O. Podunavac-Kuzmanović, D.D. Cvetković, Anion effect on antimicrobial activity of metal complexes with benzimidazole derivative, Chem. Ind. Chem. Eng. Q. 13 (2007) 68-71.

[6] M. Boiani, M. Gonzalez, Imidazole and benzimidazole derivatives as chemotherapeutic agents, Mini Rev. Med. Chem. 5 (2005) 409-415.

[7] L. Garuti, M. Roberti, C. Cermelli, Synthesis and antivirial activity of some $\mathrm{N}$-benzenesulphonyl-benzemidazoles, Bioorg. Med. Chem. Lett. 9 (1999) 2525-2530.

[8] Z. Kazimierczuk, J.A. Upcroft, P. Upcroft, A. Gorska, B. Starosciak, A. Laudy, Synthesis, antiprotozoal and antibacterial activity of nitro- and halogeno- substituted benzimidazole derivatives, Acta Biochim. Polon. 49-1 (2002) 185-195.

[9] A. Akbay, I. Oren, O. Temiz-Arpaci, E. Aki-Sener, I. Yalcin, Synthesis and HIF-1 reverse transcriptase inhibitor activity of some 2,5,6-substituted benzoxazole, benzimidazole, benzothiazole and oxazolo(4,5-b)pyridine derivatives, Arzneim.-Forcsh./Drug Res. 53 (2003) 266-271.
[10] D.R. Bevan, QSAR and Drug Design, Network Science, http://www.netsci.org/Science/Compchem/feature12.html (accessed Feb, 2013).

[11] QSAR, The Australian Computational Chemistry via the Internet Project, www.chem.swin.edu.au/modukes/ mod4/index.html (accessed Feb, 2013).

[12] C. Hansch, On the structure of medicinal chemistry, J. Med. Chem. 19 (1976) 1-6.

[13] A. Leo, C. Hansch, D. Elkins, Partition coefficients and their uses, Chem. Rev. 71 (1971) 525-616.

[14] S.O. Podunavac-Kuzmanović, D.D. Cvetković, Lipophilicity and antifungal activity of some 2-substituted benzimidazole derivatives, Chem. Ind. Chem. Eng. Q. 17 (2011) 9-15.

[15] S.O. Podunavac-Kuzmanović, D.D. Cvetković, QSAR modeling of antibacterial activity of some benzimidazole derivatives, Chem. Ind. Chem. Eng. Q. 17 (2011) 33-38.

[16] N.U. Perišić-Janjić, S.O. Podunavac-Kuzmanović, RPTLC study of QSRR and QSAR for some benzimidazole derivatives, J. Planar Chromatogr. 21 (2008) 135-141.

[17] N.U. Perišić-Janjić, S.O. Podunavac-Kuzmanović, J.S. Balaž, Đ. Vlaović, Chromatographic behaviour and lipophilicity of some benzimidazole derivatives, J. Planar Chromatogr. 13 (2000) 123-129.

[18] S.O. Podunavac-Kuzmanović, D.D. Cvetković, D.J. Barna, The effect of lipophilicity on the antibacterial activity of some 1-benzylbenzimidazole derivatives, J. Serb. Chem. Soc. 73 (2008) 967-978.

[19] S.O. Podunavac-Kuzmanović, D.D. Cvetković, D.J. Barna, Correlations between the lipophilicity and the inhibitory activity of different substituted benzimidazoles, Chem. Ind. Chem. Eng. Q. 15 (2009) 125-130.

[20] S.O. Podunavac-Kuzmanović, D.D. Cvetković, D.J. Barna, QSAR Analysis of 2-Amino or 2-Methyl-1-Substituted Benzimidazoles Against Pseudomonas aeruginosa, Int. J. Mol. Sci. 10 (2009) 1670-1682.

[21] S.O. Podunavac-Kuzmanović, S.L. Markov, D.J. Barna, Relationship between the lipophilicity and antifungal activity of some benzimidazole derivatives, J. Theor. Comp. Chem. 6 (2007) 687-698.

[22] Đ. Vlaović, J. Čanadanović-Brunet, J. Balaž, I. Juranić, D. Đoković, K. Mackenzie, Synthesis, antibacterial, and antifungal activities of some new benzimidazoles, Biosci. Biotech. Biochem. 56 (1992) 199-206.

[23] National Committee for Clinical Laboratory Standards, NCCLS Approval Standard Document M2-A7, Vilanova, Pa, U.S.A., 2000.

[24] National Committee for Clinical Laboratory Standards, NCCLS Approval Standard Document M7-A5, Vilanova, Pa, U.S.A., 2000.

[25] CS. Chem. Office, Version 7.0, Cambridge Soft Corporation, 100 Cambridge Park Drive, Cambridge, MA 02140-2317, U.S.A., 2001.

[26] NCSS Statistical Software, www.ncss.com (accessed Feb, 2013).

[27] G.W. Snedecor, W.G. Cochran, Statistical Methods, Oxford and IBH, New Delhi, 1967.

[28] S. Chaltterjee, A.S. Hadi, B. Price, Regression Analysis by Examples, Wiley VCH, New York, 2000. 
[29] M.V. Diudea, QSPR/QSAR Studies for Molecular Descriptors, Nova Science, Huntingdon, New York, 2000.

[30] J.G. Topliss, R.P. Edwards, Chance factors in studies of quantitative structure-activity relationships, J. Med. Chem. 22 (1979) 1238-1244.

[31] A. Golbraikh, J. Tropsha, Beware of $q^{2}$ !, J. Mol. Graph. Mod. 20 (2002) 269-276.

[32] M. Jalali-Heravi, A. Kyani, Use of computer-assisted methods for the modeling of the retention time of a variety of volatile organic compounds: A PCA-MLR-ANN
Approach, J. Chem. Inf. Comput. Sci. 44 (2004) 1328$-1335$.

[33] H.H. Meyer, Zur theorie der alkoholnarkose. Der einfluss wechseinder temperature angsstarke auf wirkungsstarke und theilungscoefficient der narcotica, Arch. Exp. Pathol. Pharmacol. 46 (1901) 338-346.

[34] C.E. Overton, Studies of narcosis and a contribution to general pharmacology, in: Studies of Narcosis, R.L. Lipnick, Ed., Chapman and Hall and the Wood Library and the Museum of Anaesthesiology, London, 1991.

\section{IZVOD}

\section{PRIMENA QSAR MODELA U ANALIZI ANTIBAKTERIJSKE AKTIVNOSTI NEKIH DERIVATA BENZIMIDAZOLA PREMA Sarcina lutea}

Sanja O. Podunavac-Kuzmanović, Dragoljub D. Cvetković, Lidija R. Jevrić, Nataša U. Uzelac

Univerzitet u Novom Sadu, Tehnološki fakultet, Novi Sad, Srbija

(Naučni rad)

$U$ ovom radu, urađena je analiza kvantitativne zavisnosti struktura-aktivnost (QSAR) u okviru serije derivata 2-metil i 2-aminobenzimidazola, da bi se utvrdio uticaj lipofilnosti molekula na njihovu inhibitornu aktivnost prema bakteriji Sarcina lutea. Ispitivana jedinjenja in vitro pokazuju antibakterijsku aktivnost i za sva jedinjenja određena je minimalna inhibitorna koncentracija (MIC). Za ispitivana jedinjenja koeficijenti raspodele određeni su shake flask metodom $(\log P)$ i teoretskim izračunavanjem (Clog $P$ ). Ispitane su zavisnosti između deskriptora lipofilnosti i antibakterijske aktivnosti i razvijeni su matematički modeli za predviđanje inhibitorne aktivnosti ove grupe jedinjenja. Kvalitet modela potvrđen je LOO (leave-one-out) tehnikom, kao i izračunavanjem statističkih parametara za postavljene modele. QSAR analiza pokazala je značajan uticaj lipofilnosti na inhibitornu aktivnost ispitivane serije benzimidazola prema Sarcina lutea.
Ključne reči: Benzimidazol • QSAR • Lipofilnost • Antibakterijska aktivnost • Sarcina lutea 